A RATIONAL CUBIC SPLINE WITH TENSION

\author{
J.A. Gregory and M. Sarfraz
}


z163191 x 


\title{
A RATIONAL CUBIC SPLINE WITH TENSION
}

\author{
by \\ John A. Gregory and Muhammad Sarfraz \\ Department of Mathematics and Statistics \\ Brunel university, Uxbridge, UB8 3PH, UK.
}

\begin{abstract}
A rational cubic spline curve is described which has tension control parameters for manipulating the shape of the curve. The spline is presented in both interpolatory and rational B-spline forms, and the behaviour of the resulting representations is analysed with respect to variation of the control parameters.
\end{abstract}

Keywords. Rational cubic spline, Rational Bernstein-Bezier curves, tension, shape control. 


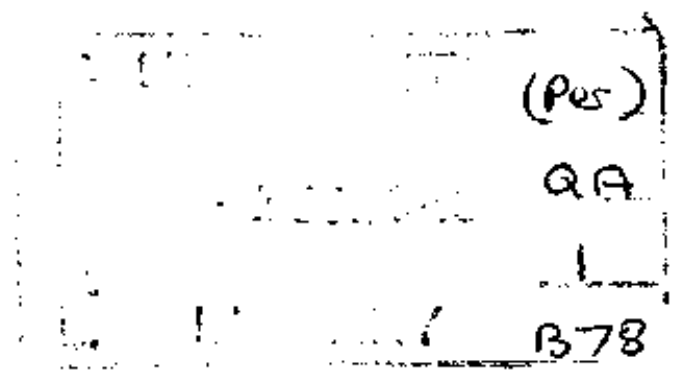




\section{Introduction}

This paper presents a description and analysis of a rational cubic tension spline for use in CAGD (Computer Aided Geometric Design). We propose to use the spline for the representation of parametric curves in both interpolatory and B-spline form, where the rational description provides tension parameters which can be used to influence the shape of the curves. The rational spline provides a computationally simpler alternative to the exponential spline-under-tension [Schweikert '66, Cline '74, Preuss 176]. It also provides an alternative to the cubic $v$-spline of Nielson [Neilson '75] and the $\beta$-spline representation of such cubics by Barsky and Beatty [Barsky and Beatty '83]. In this paper we propose to maintain the $\mathrm{C}^{2}$ parametric continuity of the curve, rather than the more general geometric $\mathrm{G} \mathrm{C}^{2}$ arc length continuity achieved by the $v$-spline and $\beta$-spline. Our approach is thus different from that of Böhm [Böhm '87] or Nielson [Nielson '84] in their development of rational geometric splines.

One similarity with the paper [Böhm '87], is that the rational spline is not restricted to the 'homogeneous coordinate' form of having a cubic spline numerator and denominator. Thus, in general, it is not a projection from a cubic spline in $\mathbb{R}^{4}$ into $\mathbb{R}^{3}$ as, for example, in the case of nonuniform rational B-splines. This, we believe, gives more freedom to develop shape control parameters for the curve, which behave in a well defined and well controlled way. For simplicity, we will describe and analyse a rational spline which has one 'tension' control parameter associated with each interval, although more parameters could be introduced into the rational form. Since the spline is defined on a non-uniform knot partition, the partition itself provides additional degrees of freedom on the curve. However, we would normally expect the parameterization to be defined either on a uniform knot partition or by cummulative chord length.

A rational spline alternative to the exponential spline-under-tension was first considered in [Späth '74] and was discussed later within a 
general setting in [Preuss '79]. The rational spline of this paper can also be considered within the setting of Preuss, but we find it more convenient to develop the properties of the rational spline per se.

The rational spline is based on earlier work, [Delbourgo and Gregory '85], in the use of a rational cubic Hermite interpolant. This interpolant is used in the development of the interpolatory rational spline presented here, see also [Gregory '86]. Particular, data dependent, choices of the tension parameters can be shown to lead to special rational forms which can be used in the construction of shape preserving scalar curve interpolants, as in [Delbourgo and Gregory 183] and [Schaback 173]. More recently, Goodman [Goodman '88] has considered $\mathrm{GC}^{2}$ shape preserving, parameteric, rational cubic spline interpolants. Here, however, we will view the tension parameters as an interactive design tool for manipulating the shape of a parametric curve.

The rational cubic Hermite interpolant is introduced in Section 2 together with some preliminary analysis. Section 3 describes the interpolatory rational spline and analyses its behaviour with respect to the tension parameters. Finally, in Section 4, a B-spline type representation of the rational spline is developed and studied.

\section{2. $C^{1}$ piecewise rational cubic Hermite interpolant}

Let $F_{i} \in R^{N}, i=0, \ldots, n$, be values given at knots $t_{i}, i=0, \ldots, n$, where $\mathrm{t}_{0}<\mathrm{t}_{1}<\ldots<\mathrm{t}_{\mathrm{n}}$, and let $\mathrm{D}_{\mathrm{i}} \in \mathrm{R}^{\mathrm{N}}, \mathrm{i}=0, \ldots, \mathrm{n}$, denote first derivative values defined at the knots. Then a piecewise rational cubic Hermite parametric function $p \in C^{1}\left[t_{0}, t_{n}\right]$ is defined for $t \in\left(t_{i}, t_{i+1}\right)$, $\mathrm{i}=0, \ldots, \mathrm{n}-1, \mathrm{by}$

$$
\begin{aligned}
P(t) & =P_{i}\left(t ; r_{i}\right) \\
& =\frac{(1-\theta)^{3} F_{i}+\theta(1-\theta)^{2}\left(r_{i} F_{i}+h_{i} D_{i}\right)+\theta^{2}(1-\theta)\left(r_{i} F_{i+1}-h_{i} D_{i+1}\right)+\theta^{3} F_{i+1}}{1+\left(r_{i}-3\right) \theta(1-\theta)}
\end{aligned}
$$


where

$$
\theta(\mathrm{t})=\left(\mathrm{t}-\mathrm{t}_{\mathrm{i}}\right) / \mathrm{h}_{\mathrm{i}}, \quad \mathrm{h}_{\mathrm{i}}=\mathrm{t}_{\mathrm{i}+1}-\mathrm{t}_{\mathrm{i}} \text { and } \mathrm{r}_{\mathrm{j}}>-1 .
$$

Here, $p \in \mathrm{C}^{1}\left[\mathrm{t}_{0}, \mathrm{t}_{\mathrm{n}}\right]$ means that each component function of $\mathrm{p}:\left[\mathrm{t}_{0}, \mathrm{t}_{\mathrm{n}}\right] \rightarrow \mathrm{R}^{\mathrm{N}}$ is continuously differentiable on $\left[\mathrm{t}_{0}, \mathrm{t}_{\mathrm{n}}\right]$. We will also use $\|\cdot\|$ to denote the uniform norm, either on $\left[\mathrm{t}_{0}, \mathrm{t}_{\mathrm{n}}\right]$ or $\left[\mathrm{t}_{\mathrm{i}}, \mathrm{t}_{\mathrm{i}+1}\right]$, this being the maximum of the uniform norm of the components of our parametric function.

The function $\mathrm{p}(\mathrm{t})$ has the Hermite interpolation properties that

$$
\mathrm{p}\left(\mathrm{t}_{\mathrm{i}}\right)=\mathrm{F}_{\mathrm{i}} \text { and } \mathrm{p}^{(1)}\left(\mathrm{t}_{\mathrm{i}}\right)=\mathrm{D}_{\mathrm{i}}, \quad \mathrm{i}=0, \ldots, \mathrm{n} .
$$

The $r_{i}, i=0, \ldots, n-1$, will be used as "tension" parameters to control the shape of the curve. The case $r_{i}=3, i=0, \ldots, n-1$, is that of cubic Hermite interpolation and the restriction $r_{i}>-1$ ensures a positive (non-zero) denominator in (2.1).

For $r_{i} \neq 0,(2.1)$ can be written in the form

$$
\mathrm{P}_{\mathrm{i}}\left(\mathrm{t} ; \mathrm{r}_{\mathrm{i}}\right)=\mathrm{R}_{0}\left(\theta ; \mathrm{r}_{\mathrm{i}}\right) \mathrm{F}_{\mathrm{i}}+\mathrm{R}_{1}\left(\theta ; \mathrm{r}_{\mathrm{i}}\right) \mathrm{V}_{\mathrm{i}}+\mathrm{R}_{2}\left(\theta ; \mathrm{r}_{\mathrm{i}}\right) \mathrm{W}_{\mathrm{i}}+\mathrm{R}_{3}\left(\theta ; \mathrm{r}_{\mathrm{i}}\right) \mathrm{F}_{\mathrm{i}+1}
$$

where

$$
\mathrm{V}_{\mathrm{i}}=\mathrm{F}_{\mathrm{i}}+\mathrm{h}_{\mathrm{i}} \mathrm{D}_{\mathrm{i}} / \mathrm{r}_{\mathrm{i}}, \quad \mathrm{W}_{\mathrm{i}}=\mathrm{F}_{\mathrm{i}+1}-\mathrm{h}_{\mathrm{i}} \mathrm{D}_{\mathrm{i}+1} / \mathrm{ri},
$$

and the $\mathrm{R}_{\mathrm{i}}\left(\theta ; \mathrm{r}_{\mathrm{i}}\right)$ are appropriately defined rational functions with

$$
\sum_{j=0}^{3} R_{j}\left(\theta ; r_{i}\right)=1
$$

Moreover, these functions are rational Bernstein-Bezier weight functions which are non-negative for $r_{i}>0$, since the denominator in (2.1) can be written as

$$
(1-\theta)^{3}+r_{i} \theta(1-\theta)^{2}+r_{i} \theta^{2}(1-\theta)+\theta^{3} .
$$

Thus in $\mathrm{IR}^{\mathrm{N}}, \mathrm{N}>1$ and for $\mathrm{r}_{\mathrm{i}}>0$ :

(i) (Convex hull property) The curve segment $\mathrm{P}_{\mathrm{i}}$ lies in the convex hull of the control points $\left\{\mathrm{F}_{\mathrm{i}}, \mathrm{V}_{\mathrm{i}}, \mathrm{W}_{\mathrm{i}}, \mathrm{F}_{\mathrm{i}+1}\right\}$.

(ii) (Variation diminishing property) The curve segment $\mathrm{P}_{\mathrm{i}}$ crosses any (hyper) plane of dimension $\mathrm{N}-1$ no more times than it crosses the "control polygon" joining $F_{i}, V_{i}, W_{i}, F_{i+1}$, (See [Goodman '89].) 
Remark 2.1 In the scalar case $\mathrm{N}=1$, properties (i) and (ii) apply to the curve segment $\left(t, P_{i}\left(t ; r_{i}\right)\right) \in \mathbb{R}^{2}, t \in\left(t_{i}, t_{i+1}\right)$, with control points

$$
\left\{\left(\mathrm{t}_{\mathrm{i}}, \mathrm{F}_{\mathrm{i}}\right),\left(\mathrm{t}_{\mathrm{i}}+\mathrm{h}_{\mathrm{i}} / \mathrm{r}_{\mathrm{i}}, \mathrm{V}_{\mathrm{i}}\right),\left(\mathrm{t}_{\mathrm{i}+1}-\mathrm{h}_{\mathrm{i}} / \mathrm{r}_{\mathrm{i}}, \mathrm{W}_{\mathrm{i}}\right),\left(\mathrm{t}_{\mathrm{i}+1}, \mathrm{~F}_{\mathrm{i}+1}\right)\right\}
$$

This is a consequence of the identity

$$
\mathrm{t} \equiv \mathrm{R}_{0}\left(\theta ; \mathrm{r}_{\mathrm{i}}\right) \mathrm{t}_{\mathrm{i}}+\mathrm{R}_{1}\left(\theta ; \mathrm{r}_{\mathrm{i}}\right)\left(\mathrm{t}_{\mathrm{i}}+\mathrm{h}_{\mathrm{i}} / \mathrm{r}_{\mathrm{i}}\right)+\mathrm{R}_{2}\left(\theta ; \mathrm{r}_{\mathrm{i}}\right)\left(\mathrm{t}_{\mathrm{i}+1}-\mathrm{h}_{\mathrm{i}} / \mathrm{r}_{\mathrm{i}}\right)+\mathrm{R}_{3}\left(\theta ; \mathrm{r}_{\mathrm{i}}\right) \mathrm{t}_{\mathrm{i}+1}
$$

In fact, $(\mathrm{t}, \mathrm{p}(\mathrm{t}))$ can be considered as an application of the interpolation scheme in $\mathrm{R}^{2}$ to the values $\left(\mathrm{t}_{\mathrm{i}}, \mathrm{F}_{\mathrm{i}}\right) \in \mathrm{R}^{2}$ and derivatives $\left(1, \mathrm{D}_{\mathrm{i}}\right) \in \mathrm{R}^{2}$, $\mathrm{i}=0, \ldots, \mathrm{n}$.

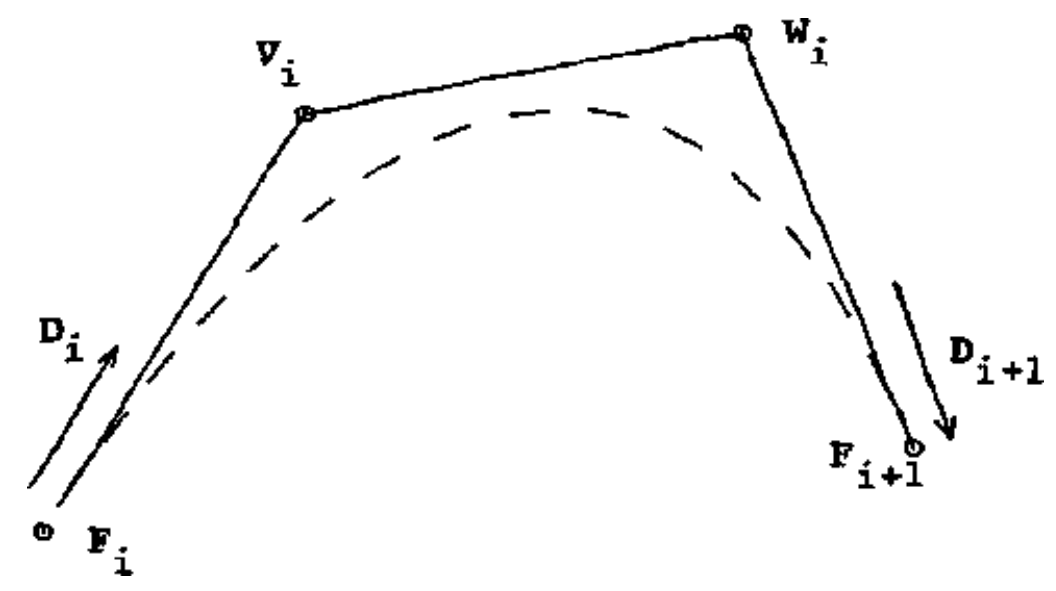

Figure 2.1. The rational cubic segment in $\mathrm{R}^{2}$

The rational cubic (2.1) can be written in the form

$$
\mathrm{p}_{\mathrm{i}}\left(\mathrm{t} ; \mathrm{r}_{\mathrm{i}}\right)=\ell_{\mathrm{i}}(\mathrm{t})+\mathrm{e}_{\mathrm{i}}\left(\mathrm{t} ; \mathrm{r}_{\mathrm{i}}\right)
$$

where

$$
\begin{aligned}
& \ell_{\mathrm{i}}(\mathrm{t})=(1-\theta) \mathrm{F}_{\mathrm{i}}+\theta \mathrm{F}_{\mathrm{i}+1}, \\
& \mathrm{e}_{\mathrm{i}}\left\{\mathrm{t} ; \mathrm{r}_{\mathrm{i}}\right\}=\frac{\mathrm{h}_{\mathrm{i}} \theta(1-\theta)\left\{\left(\Delta_{\mathrm{i}}-\mathrm{D}_{\mathrm{i}}\right)(\theta-1)+\left(\Delta_{\mathrm{i}}-\mathrm{D}_{\mathrm{i}+1}\right) \theta\right\}}{1+\left(\mathrm{r}_{\mathrm{i}}-3\right) \theta(1-\theta)} \\
& \Delta_{\mathrm{i}}=\left(\mathrm{F}_{\mathrm{i}+1}-\mathrm{F}_{\mathrm{i}}\right) / \mathrm{h}_{\mathrm{i}} .
\end{aligned}
$$

This immediately leads to: 
Proposition 2.2 (Tension property) The rational cubic Hermite interpolant (2.1) coverges uniformly to the linear interpolant (2.10) on $\left[\mathrm{t}_{\mathrm{i}}, \mathrm{t}_{\mathrm{i}+1}\right]$ as $\mathrm{r}_{\mathrm{i}} \rightarrow \infty$, , i.e.

$$
\lim _{r_{i} \rightarrow \infty}\left\|e_{i}\right\|=\lim _{r_{i} \rightarrow \infty}\left\|P_{i}-\ell_{i}\right\|=0
$$

Moreover, the component functions of $e_{i}$ tend to zero monotonically, both uniformly and pointwise on $\left[\mathrm{t}_{\mathrm{i}}, \mathrm{t}_{\mathrm{i}+1}\right]$.

Remark 2.3. The tension property can also be observed from the behaviour of the control points $\mathrm{V}_{\mathrm{i}}, \mathrm{W}_{\mathrm{i}}$ defined by (2.6), and hence of the Bernstein- Bézier convex hull, as $r_{i} \rightarrow \infty$.

In the following section, a $\mathrm{C}^{2}$ rational spline interpolant will be constructed. This requires knowledge of the 2 'nd derivative of (2.1) which, after some simplification, is given by

$$
\mathrm{P}_{\mathrm{i}}^{(2)}\left(\mathrm{t} ; \mathrm{r}_{\mathrm{i}}\right)=\frac{2\left\{\alpha_{\mathrm{i}} \theta^{3}+\beta_{\mathrm{i}} \theta^{2}(1-\theta)+\gamma_{\mathrm{i}} \theta(1-\theta)^{2}+\delta_{\mathrm{i}}(1-\theta)^{3}\right\}}{\mathrm{h}_{\mathrm{i}}\left\{1+\left(\mathrm{r}_{\mathrm{i}}-3\right) \theta(1-\theta)\right\}^{3}},
$$

Where

$$
\left.\begin{array}{l}
\alpha_{i}=r_{i}\left(D_{i+1}-\Delta_{i}\right)-D_{i+1}+D_{i}, \\
\beta_{i}=3\left(D_{i+1}-\Delta_{i}\right), \\
\gamma_{i}=3\left(\Delta_{i}-D_{i}\right), \\
\delta_{i}=r_{i}\left(\Delta_{i}-D_{i}\right)-D_{i+1}+D_{i}
\end{array}\right\}
$$

\section{3. $\mathrm{C}^{2}$ rational cubic spline interpolant}

We now follow the familiar procedure of allowing the derivative parameters $D_{i}, i=0, \ldots, n$, to be degrees of freedom which are constrained by the imposition of the $\mathrm{C}^{2}$ continuity conditions

$$
\mathrm{P}^{(2)}\left(\mathrm{t}_{\mathrm{i}+}\right)=\mathrm{P}^{(2)}\left(\mathrm{t}_{\mathrm{i}-}\right), \quad \mathrm{i}=1 \ldots, \mathrm{n}-1
$$

These $\mathrm{C}^{2}$ conditions give, from (2.13) and (2.14), the linear system of "consistency equations"

$\mathrm{h}_{\mathrm{i}} \mathrm{D}_{\mathrm{i}-1}+\left\{\mathrm{h}_{\mathrm{i}}\left(\mathrm{r}_{\mathrm{i}-1}-1\right)+\mathrm{h}_{\mathrm{i}-1}\left(\mathrm{r}_{\mathrm{i}}-1\right)\right\} \mathrm{D}_{\mathrm{i}}+\mathrm{h}_{\mathrm{i}-1} \mathrm{D}_{\mathrm{i}+1}=\mathrm{h}_{\mathrm{i}} \mathrm{r}_{\mathrm{i}-1} \Delta_{\mathrm{i}-1}+\mathrm{h}_{\mathrm{i}-1} \mathrm{r}_{\mathrm{i}} \Delta_{\mathrm{i}}, \mathrm{i}=1, \ldots, \mathrm{n}-1$, 
where the $\Delta_{i}, \mathrm{i}=0, \ldots, \mathrm{n}-1$, are defined by (2.12). For simplicity of presentation, assume that $\mathrm{D}_{0}$ and $\mathrm{D}_{\mathrm{n}}$ are given as end conditions (clearly other end conditions are also appropriate). Assume also that

$$
\mathrm{r}_{\mathrm{i}} \geq \mathrm{r}>2, \quad \mathrm{i}=0, \ldots, \mathrm{n}-1
$$

Then (3.2) defines a diagonally dominant, tri-diagonal linear system in the unknowns $\mathrm{D}_{\mathrm{i}}, \mathrm{i}=1, \ldots, \mathrm{n}-\mathrm{l}$. Hence there exists a unique solution which can be easily calculated by use of the tri-diagonal LU decomposition algorithm. Thus a rational cubic spline interpolant can be constructed with tension parameters $r_{i}, \quad i=0, \ldots, n-1$, where the special case $r_{i}=3, i=0, \ldots, n-1$, is that of cubic spline interpolation. We now examine the behaviour of the rational spline interpolant with respect to the tension parameters $r_{i}$ in the following three propositions:

Proposition 3.1. (Global tension property) Let $\ell \in \mathrm{c}^{0}\left[\mathrm{t}_{0}, \mathrm{t}_{\mathrm{n}}\right]$ denote the piecewise linear interpolant defined for $\mathrm{t} \in\left(\mathrm{t}_{\mathrm{i}}, \mathrm{t}_{\mathrm{i}+1}\right)$ by $\ell(\mathrm{t})=\ell_{\mathrm{i}}(\mathrm{t})$, see (2.10). Suppose that $r_{i} \geq \mathrm{r}>2, \quad \mathrm{i}=0, \ldots, \mathrm{n}-1$, as in (3.3). Then the rational spline interpolant converges uniformly to $\ell$ as $r \rightarrow \infty$, i.e. on $\left[\mathrm{t}_{0}, \mathrm{t}_{\mathrm{n}}\right]$

$$
\lim _{\mathrm{r} \rightarrow \infty}\|\mathrm{p}-\ell\|=0
$$

Proof. Suppose $r_{i}=r, i=0, \ldots, n-1$. Then from (3.2) it follows that

$$
\lim _{\mathrm{r} \rightarrow \infty} \mathrm{D}_{\mathrm{i}}=\left(\mathrm{h}_{\mathrm{i}} \Delta_{\mathrm{i}-1}+\mathrm{h}_{\mathrm{i}-1} \Delta_{\mathrm{i}}\right) /\left(\mathrm{h}_{\mathrm{i}}+\mathrm{h}_{\mathrm{i}-1}\right), \mathrm{i}=1 \ldots ., \mathrm{n}-1 .
$$

More generally, for $r_{i}$ satisfying (3.3), it can be shown that

$$
\max _{1 \leq \mathrm{i} \leq \mathrm{n}-1}\left\|\mathrm{D}_{\mathrm{i}}\right\|_{\infty} \leq \max \left\{\|\Delta\|_{\infty} \mathrm{r} /(\mathrm{r}-2),\left\|\mathrm{D}_{0}\right\|_{\infty},\left\|\mathrm{D}_{\mathrm{n}}\right\|_{\infty}\right\}
$$

where

$$
\|\Delta\|_{\infty}=\max _{1 \leq \mathrm{i} \leq \mathrm{n}-1}\left\|\Delta_{\mathrm{i}}\right\|_{\infty}
$$

Hence the solution $\mathrm{D}_{\mathrm{i}}, \quad \mathrm{i}=1, \ldots, \mathrm{n}-1$, of the consistency equations (2.3) is bounded with respect to r. Now, from (2.11), the tension property (2.13) of Proposition 2.2 can clearly be extended to the case of bounded $\mathrm{D}_{\mathrm{i}}$. Thus 
applying (2.13) on each interval gives the desired result (3.4).

Proposition 3.2. (Local tension property) Consider an interval $\left[\mathrm{t}_{\mathrm{k},}, \mathrm{t}_{\mathrm{k}+1}\right]$ for a fixed $\mathrm{k} \in\{0, \ldots, \mathrm{n}-1\}$ and let the tension parameters $\mathrm{r}_{\mathrm{i}}, \mathrm{i} \neq \mathrm{k}$, be considered as functions of $r_{k}$, where $r_{i}=r_{i}\left(r_{k}\right) \geq r>2$. Then, on $\left[\begin{array}{ll}t_{k}, & t_{k+1}\end{array}\right]$, the national spline interpolant converges uniformly to the line segment $\ell_{\mathrm{k}}$ as $\mathrm{r}_{\mathrm{k}} \rightarrow \infty$, i.e.

$$
\mathrm{lim}_{\mathrm{k} \rightarrow \infty}\left\|\mathrm{P}_{\mathrm{k}}-\ell_{\mathrm{k}}\right\|=0
$$

Proof. The boundedness property (3.6) holds as in Proposition 3.1 (where we can assume the additional constraint $\mathrm{r}_{\mathrm{k}} \geq \mathrm{r}>2$ to the hypotheses currently being imposed). Thus (2.13) applies for the case $\mathrm{i}=\mathrm{k}$. $\square$ Remark 3.3. In the case of fixed $r_{i}, i \neq k$, an analysis of the linear system (3.2) shows that

$$
\lim _{\mathrm{r}_{\mathrm{k}} \rightarrow \infty}\left\|\mathrm{D}_{\mathrm{k}}-\Delta_{\mathrm{k}}\right\|_{\infty}=\mathrm{lim}_{\mathrm{k} \rightarrow \infty}\left\|\mathrm{D}_{\mathrm{k}+1}-\Delta_{\mathrm{k}}\right\|_{\infty}=0
$$

This property reinforces the rate of convergence to zero of $e_{k}=p_{k}-\ell_{k}$ in (3.8), as can be seen from (2.11) with $\mathrm{i}=\mathrm{k}$. The following proposition shows that the influence of $r_{k}$ in this case has an exponential decay away from the interval $\left[\mathrm{t}_{\mathrm{k}}, \mathrm{t}_{\mathrm{k}+1}\right]$.

Proposition 3.4. (Exponential decay property) Let $\mathrm{D}_{\mathrm{i}}, \mathrm{i}=1, \ldots, \mathrm{n}-1$, denote the solution of the consistency equations with tension parameters $\mathrm{r}_{\mathrm{i}} \geq \mathrm{r}>2, \mathrm{i}=0, \ldots, \mathrm{n}-1$, and let $\hat{\mathrm{D}}_{\mathrm{i}}, \mathrm{i}=1, \ldots, \mathrm{n}-1$, denote the solution with parameters $\hat{r}_{i} \geq r>2, i=0, \ldots, n-1$, where $\hat{r}_{i}=r_{i}$, for $\mathrm{i} \neq \mathrm{k}$. Then

$$
\left\|\mathrm{D}_{\mathrm{i}}-\widehat{\mathrm{D}}_{\mathrm{i}}\right\|_{\infty} \leq \frac{4 \gamma^{\mathrm{m}}(1+2 \gamma)}{1-\gamma}\|\Delta\|_{\infty} \text { for } \mathrm{i}=\mathrm{k}-\mathrm{m} \text { and } \mathrm{i}=\mathrm{k}+1+\mathrm{m}, \mathrm{i} \in(0, \ldots, \mathrm{n}-1)
$$

where $\|\Delta\|_{\infty}$ is the constant defined in (3.7) and

$$
\gamma=1 /(\mathrm{r}-1)<1
$$

( Thus, for example, if $r=3$ then $\gamma=1 / 2$.)

The proof of this result is based on an analysis of the consistency 
equations expressed in the matrix forms

$$
(\mathrm{I}+\mathrm{F}) \mathrm{D}=\mathrm{b} \text { and }(\mathrm{I}+\hat{\mathrm{F}}) \hat{\mathrm{D}}=\mathrm{b} .
$$

Here $\mathrm{F}$ and $\hat{\mathrm{F}}$ are tri-diagonal matrices with zero diagonals which agree in rows $\mathrm{i}, \mathrm{i} \neq \mathrm{k}, \mathrm{k}+1$ as do also the right hand sides $\mathrm{b}$ and $\hat{\mathrm{b}}$. Now

$$
\mathrm{D}-\hat{\mathrm{D}}=\left[(\mathrm{I}+\mathrm{F})^{-1}-(\mathrm{I}+\hat{\mathrm{F}})^{-1}\right] \mathrm{b}+(\mathrm{I}+\hat{\mathrm{F}})^{-1}(\mathrm{~b}-\hat{\mathrm{b}}) .
$$

An appropriate perturbation analysis of the first term of the right hand side, together with an analysis of $(\mathrm{I}+\hat{\mathrm{F}})^{-1}$ which follows that of [Demko '77] \{see his Proposition 2.1), then gives the desired result. The details of the proof are lengthy and hence, for brevity, are omitted here. Examples 3.4. The tension behaviour of rational cubic spline interpolants is illustrated by the following simple examples for a data set in $R^{2}$. Figures 3.1 show the effect of a progressive increase in global tension from $r=3$ (the cubic spline case) to $r=50$. The effect of the high tension parameter is clearly seen in that the resulting interpolant approaches piecewise linear form.
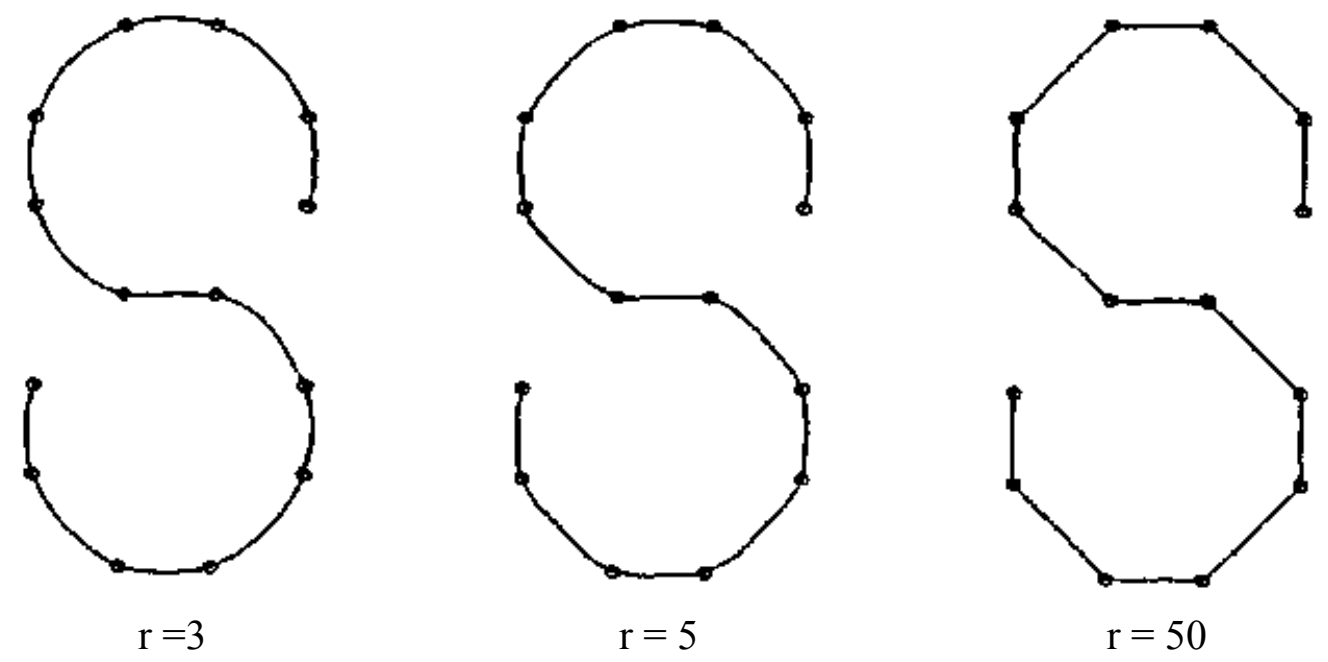

Figures 3.1 Rational spline interpolants with global tension $r_{i}=r$ 

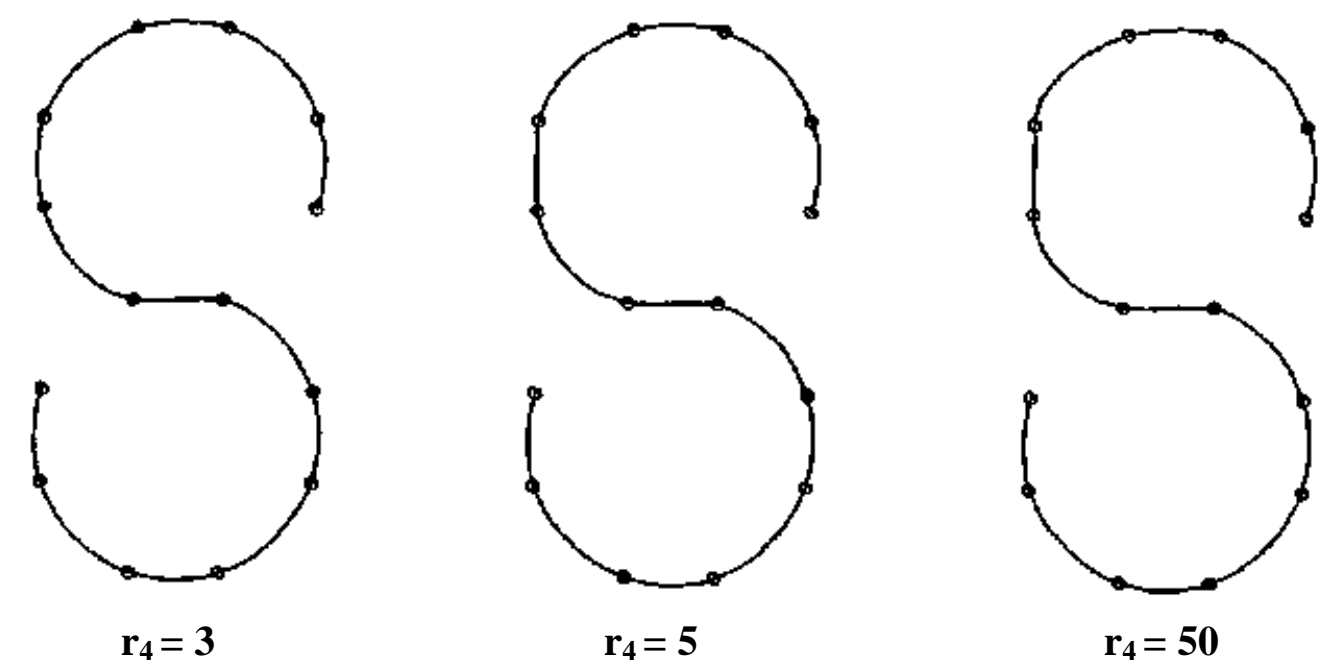

Figures 3.2 Rational spline interpolants with tension $r_{4}$ varying

The Figures 3.2 illustrate the effect of progressively increasing the value of a tension parameter in one interval, whilst elsewhere the tension parameters are fixed. A progressive 'local' flattening of the curve can be seen.

\section{Rational cubic B-spline representation}

In this section we propose the construction of a local support rational cubic B-spline basis. A method for evaluating the rational cubic B-spline representation of a curve will be suggested by a transformation to piecewise defined rational Bernstein-Bezier form. This form will also expedite a proof of the variation diminishing property for the rational B-spline representation.

For the purposes of the analysis, let additional knots be introduced outside the interval $\left[\mathrm{t}_{0}, \mathrm{t}_{\mathrm{n}}\right]$, defined by $\mathrm{t}_{-3}<\mathrm{t}_{-2}<\mathrm{t}_{-1}<\mathrm{t}_{-0}$ and $\mathrm{t}_{\mathrm{n}}<\mathrm{t}_{\mathrm{n}+1}<\mathrm{t}_{\mathrm{n}+2}<\mathrm{t}_{\mathrm{n}+3}$. Let

$$
r_{i} \geq r>2, i=-3, \ldots, n+2
$$

be tension parameters defined on this extended partition. Rational cubic 
spline functions $\psi_{\mathrm{j}}, \mathrm{j}=-1, \ldots, \mathrm{n}+3$, can be constructed, see Figure 4.1, such that

$$
\psi_{j}(t)=\left\{\begin{array}{l}
0 \text { for } \mathrm{t}<\mathrm{t}_{\mathrm{j}-2}, \\
\psi_{\mathrm{j}}\left(\mathrm{t}_{\mathrm{j}}\right)+\mathrm{t}-\mathrm{t}_{\mathrm{j}} \text { for } \mathrm{t} \geq \mathrm{t}_{\mathrm{j}} .
\end{array}\right.
$$

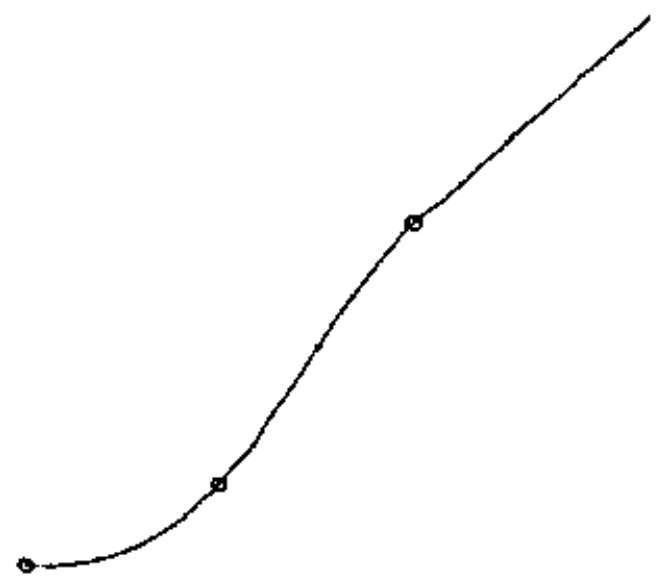

Figure 4.1 The rational spline $\psi_{\mathrm{j}}$

On the two intervals $\left[\mathrm{t}_{\mathrm{i}}, \mathrm{t}_{\mathrm{i}+1}\right), \quad \mathrm{i}=\mathrm{j}-2, \mathrm{j}-1, \quad \psi_{\mathrm{j}}$ will have the rational cubic form

$$
\begin{aligned}
\psi_{\mathrm{j}}(\mathrm{t})=\mathrm{R}_{0}\left(\theta ; \mathrm{r}_{\mathrm{i}}\right) \psi_{\mathrm{j}}\left(\mathrm{t}_{\mathrm{i}}\right)+\mathrm{R}_{1}\left(\theta ; \mathrm{r}_{\mathrm{i}}\right)\left(\psi_{\mathrm{j}}\left(\mathrm{t}_{\mathrm{i}}\right)+\mathrm{h}_{\mathrm{i}} \psi_{\mathrm{j}}^{(1)}\left(\mathrm{t}_{\mathrm{i}}\right) / \mathrm{r}_{\mathrm{i}}\right) \\
\quad+\mathrm{R}_{2}\left(\theta ; \mathrm{r}_{\mathrm{i}}\right)\left(\psi_{\mathrm{j}}\left(\mathrm{t}_{\mathrm{i}+1}\right)-\mathrm{h}_{\mathrm{i}} \psi_{\mathrm{j}}^{(1)}\left(\mathrm{t}_{\mathrm{i}+1}\right) / \mathrm{r}_{\mathrm{i}}\right)+\mathrm{R}_{3}\left(\theta ; \mathrm{r}_{\mathrm{i}}\right) \psi_{\mathrm{j}}\left(\mathrm{t}_{\mathrm{i}+1}\right) .
\end{aligned}
$$

The requirement that $\psi_{\mathrm{j}} \in \mathrm{c}^{2}(-\infty, \infty)$ (in particular at $\mathrm{t}_{\mathrm{j}-2}, \mathrm{t}_{\mathrm{j}-1}$ and $\mathrm{t}_{\mathrm{j}}$ ) uniquely determines $\psi_{\mathrm{j}}$, since it can then be shown that

$$
\left.\begin{array}{l}
\psi_{\mathrm{j}}\left(\mathrm{t}_{\mathrm{j}-2}\right)=\psi_{\mathrm{j}}^{(\mathrm{i})}\left(\mathrm{t}_{\mathrm{j}-2}\right)=0 \\
\psi_{\mathrm{j}}\left(\mathrm{t}_{\mathrm{j}-1}\right)=\mathrm{d}_{\mathrm{j}-1} \mathrm{~h}_{\mathrm{j}-2} / \mathrm{r}_{\mathrm{j}-2,}, \psi_{\mathrm{j}}^{(1)}\left(\mathrm{t}_{\mathrm{j}-1}\right)=\mathrm{d}_{\mathrm{j}-1} \\
\psi_{\mathrm{j}}\left(\mathrm{t}_{\mathrm{j}}\right)=\mathrm{d}_{\mathrm{j}-1}\left(\mathrm{~h}_{\mathrm{j}-1} / \mathrm{r}_{\mathrm{j}-1}+\mathrm{h}_{\mathrm{j}-2} / \mathrm{r}_{\mathrm{j}-2}\right)+\mathrm{h}_{\mathrm{j}-1}\left(1-1 / \mathrm{r}_{\mathrm{j}-1}\right), \psi_{\mathrm{j}}^{(1)}\left(\mathrm{t}_{\mathrm{j}}\right)=1,
\end{array}\right\}
$$

Where

$$
d_{j}=h_{j-1}\left(r_{j}-2\right) /\left(h_{j}\left(r_{j-1}-2\right)+h_{j-1}\left(r_{j}-2\right)\right)
$$

It should be noted that $\psi_{\mathrm{j}}$ is a member of our class of rational spline 
functions, since the class of rational cubic functions contains all polynomials of degree 1 (see identities (2.8) and (2.9)). Hence the linear extension in (4.2) for $t \geq t_{j}$ is allowable.

The local support rational cubic B-spline basis is now defined by the difference functions

where

$$
\mathrm{B}_{\mathrm{j}}(\mathrm{t})=\varphi_{\mathrm{j}}(\mathrm{t})-\varphi_{\mathrm{j}+1}(\mathrm{t}), \quad \mathrm{j}=-1, \ldots, \mathrm{n}+1
$$

$$
\varphi_{\mathrm{j}}(\mathrm{t})=\left(\psi_{\mathrm{j}}(\mathrm{t})-\psi_{\mathrm{j}+1}(\mathrm{t})\right) / \mathrm{c}_{\mathrm{j},}, \quad \mathrm{j}=-1, \ldots, \mathrm{n}+2
$$

and

$$
\begin{aligned}
\mathrm{c}_{\mathrm{j}} & =\psi_{\mathrm{j}}\left(\mathrm{t}_{\mathrm{j}+1}\right)-\psi_{\mathrm{j}+1}\left(\mathrm{t}_{\mathrm{j}+1}\right) \\
& =\mathrm{d}_{\mathrm{j}-1}\left(\mathrm{~h}_{\mathrm{j}-1} / \mathrm{r}_{\mathrm{j}-1}+\mathrm{h}_{\mathrm{j}-2} / \mathrm{r}_{\mathrm{j}-2}\right)+\left(1-\mathrm{d}_{\mathrm{j}}\right)\left(\mathrm{h}_{\mathrm{j}} / \mathrm{r}_{\mathrm{j}}+\mathrm{h}_{\mathrm{j}-1} / \mathrm{r}_{\mathrm{j}-1}\right)+\mathrm{h}_{\mathrm{j}-1}\left(1-2 / \mathrm{r}_{\mathrm{j}-1}\right) .
\end{aligned}
$$

It should be observed that $\psi_{\mathrm{j}}$ has been constructed such that

$$
\varphi_{j}(\mathrm{t})= \begin{cases}0 & \text { for } \mathrm{t}<\mathrm{t}_{\mathrm{j}-2} . \\ 1 & \text { for } \mathrm{t} \geq \mathrm{t}_{\mathrm{j}+1} .\end{cases}
$$

Thus, there immediately follows:

Proposition 4.1. (Rational B-spline) The rational spline functions $B_{j}(t), j=-1, \ldots, n+1$, are such that

$$
\begin{aligned}
& \text { (Local support) } B_{j}(t)=0 \text { for } t \notin\left(t_{j-2}, t_{j+2}\right) . \\
& \text { (Partition of unity) } \sum_{j=-1}^{n+1} B_{j}(t)=1 \text { for } t \in\left[t_{0}, t_{n}\right] \text {. }
\end{aligned}
$$

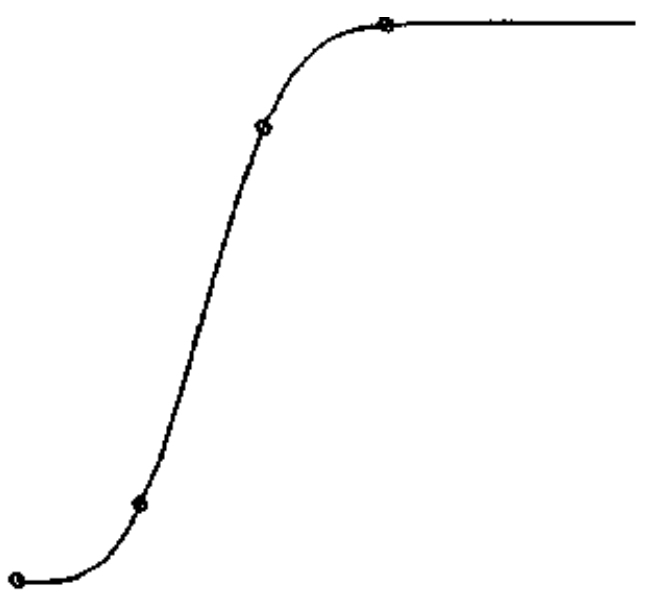

Figure 4.2 The rational spline $\varphi_{\mathrm{j}}(\mathrm{t})$ 


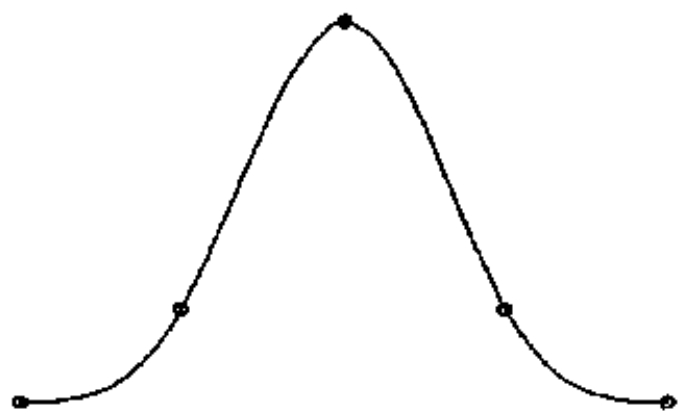

Figure 4.3 The rational $B$-spline $B_{j}(t)$

An explicit representation of the rational cubic $B$-spline $B_{j}$ on any interval $\left[\mathrm{t}_{\mathrm{i}}, \mathrm{t}_{\mathrm{i}+1}\right)$ can be calucalted from (4.2)-(4.8) as

$$
\begin{aligned}
\mathrm{B}_{\mathrm{j}}(\mathrm{t})= & \mathrm{R}_{0}\left(\theta ; \mathrm{r}_{\mathrm{i}}\right) \mathrm{B}_{\mathrm{j}}\left(\mathrm{t}_{\mathrm{i}}\right)+\mathrm{R}_{1}\left(\theta ; \mathrm{t}_{\mathrm{i}}\right)\left(\mathrm{B}_{\mathrm{j}}\left(\mathrm{t}_{\mathrm{i}}\right)+\mathrm{h}_{\mathrm{i}} \mathrm{B}_{\mathrm{j}}^{(1)}\left(\mathrm{t}_{\mathrm{i}}\right) / \mathrm{r}_{\mathrm{i}}\right) \\
& +\mathrm{R}_{2}\left(\theta ; \mathrm{r}_{\mathrm{i}}\right) \mathrm{B}_{\mathrm{j}}\left(\mathrm{t}_{\mathrm{i}+1}\right)-\mathrm{h}_{\mathrm{i}} \mathrm{B}_{\mathrm{j}}^{(1)}\left(\mathrm{t}_{\mathrm{i}+1}\right) / \mathrm{r}_{\mathrm{i}}+\mathrm{R}_{3}\left(\theta ; \mathrm{r}_{\mathrm{i}}\right) \mathrm{B}_{\mathrm{j}}\left(\mathrm{t}_{\mathrm{i}+1}\right)
\end{aligned}
$$

where

$$
B_{j}\left(t_{1}\right)=B_{j}^{(1)}\left(t_{1}\right)=0 \text { for } i \neq j-1, j, j+1
$$

and

$$
\begin{array}{ll}
B_{j}\left(t_{j-1}\right)=\mu_{j-1}, & B_{j}^{(1)}\left(t_{j-1}\right)=\hat{\mu}_{j-1}, \\
B_{j}\left(t_{j}\right)=1-\lambda_{j}-\mu_{j}, & B_{j}^{(1)}\left(t_{j}\right)=\hat{\lambda}_{j}-\hat{\mu}, \\
B_{j}\left(t_{j+1}\right)=\lambda_{j+1}, & B_{j}^{(1)}\left(t_{j+1}\right)=-\hat{\lambda}_{j+1},
\end{array}
$$

with

$$
\left.\begin{array}{l}
\hat{\mu}_{\mathrm{j}}=\mathrm{d}_{\mathrm{j}} / \mathrm{c}_{\mathrm{j}+1}, \quad \mu_{\mathrm{j}}=\mathrm{h}_{\mathrm{j}-1} \hat{\mu}_{\mathrm{j}} / \mathrm{r}_{\mathrm{j}-1}, \\
\hat{\lambda}=\left(1-\mathrm{d}_{\mathrm{j}}\right) / \mathrm{c}_{\mathrm{j}}, \quad \lambda_{\mathrm{j}}=\mathrm{h}_{\mathrm{j}} \hat{\lambda}_{\mathrm{j}} / \mathrm{r}_{\mathrm{j}} .
\end{array}\right\}
$$


Careful examination of the Bernstein-Bezier vertices of $B_{j}(t)$ in(4.12) show these to be non-negative for $r_{i}$ satisfying (4.1) and we thus have:

Proposition 4.2 The rational B-spline functions are such that

$$
\text { (Positivity) } B_{\mathrm{j}}(\mathrm{t}) \geq 0 \text { for all } \mathrm{t} \text {. }
$$

To apply the rational cubic B-spline as a practical method for curve design, a convenient method for computing the curve representation

$$
p(t)=\sum_{j=-1}^{n+1} B_{j}(t) p_{j}, \quad t \in\left[t_{0}, t_{n}\right]
$$

is required, where $p_{j} \in R^{N}$ define the control points of the representation. Now, by the local support property,

$$
p(t)=\sum_{j=i-1}^{i+2} B_{j}(t) p_{j}, \quad t \in\left[t_{i}, t_{i+1}\right), \quad i=0, \ldots, n-1
$$

Substitution of $(4+.12)$ then gives the piecewise defined rational BernsteinBézier representation

$$
\mathrm{p}(\mathrm{t})=\mathrm{R}_{0}\left(\theta ; \mathrm{r}_{\mathrm{i}}\right) \mathrm{F}_{\mathrm{i}}+\mathrm{R}_{\mathrm{i}}\left(\theta ; \mathrm{r}_{\mathrm{i}}\right) \mathrm{V}_{\mathrm{i}}+\mathrm{R}_{2}\left(\theta ; \mathrm{r}_{\mathrm{i}}\right) \mathrm{W}_{\mathrm{i}}+\mathrm{R}_{3}\left(\theta ; \mathrm{r}_{\mathrm{i}}\right) \mathrm{F}_{\mathrm{I}+1}, \quad \mathrm{t} \in\left[\mathrm{t}_{\mathrm{i}}, \mathrm{t}_{\mathrm{i}+1}\right)
$$

where

With

$$
\left.\begin{array}{l}
\mathrm{F}_{\mathrm{i}}=\lambda_{\mathrm{i}} \mathrm{P}_{\mathrm{i}-1}+\left(1-\lambda_{\mathrm{j}}-\mu\right) \mathrm{P}_{\mathrm{i}}+\mu_{\mathrm{i}} \mathrm{P}_{\mathrm{i}+1}, \\
\mathrm{~V}_{\mathrm{i}}=\left(1-\alpha_{\mathrm{i}}\right) \mathrm{P}_{\mathrm{i}}+\alpha_{\mathrm{i}} \mathrm{P}_{\mathrm{i}+1}, \\
\mathrm{~W}_{\mathrm{i}}=\beta_{\mathrm{i}} \mathrm{P}_{\mathrm{i}}+\left(1-\beta_{\mathrm{i})}\right) \mathrm{P}_{\mathrm{i}+1},
\end{array}\right\}
$$

$$
\left.\begin{array}{l}
\alpha_{\mathrm{i}}=\mu_{\mathrm{i}}+\mathrm{h}_{\mathrm{i}} \hat{\mu}_{\mathrm{i}} / \mathrm{r}_{\mathrm{i}}=\hat{\mu}_{\mathrm{i}}\left(\mathrm{h}_{\mathrm{i}-1} / \mathrm{r}_{\mathrm{i}-1}+\mathrm{h}_{\mathrm{i}} / \mathrm{r}_{\mathrm{i}}\right), \\
\beta_{\mathrm{i}}=\lambda_{\mathrm{i}+1}+\mathrm{h}_{\mathrm{i}} \hat{\lambda}_{\mathrm{i}+1} / \mathrm{r}_{\mathrm{i}}=\hat{\lambda}_{\mathrm{i}+1}\left(\mathrm{~h}_{\mathrm{i}} / \mathrm{r}_{\mathrm{i}}+\mathrm{h}_{\mathrm{i}+1} / \mathrm{r}_{\mathrm{i}+1}\right)
\end{array}\right\}
$$

This transformation to rational Bernstein-Bézier form is very convenient for computational purposes and also leads to:

Proposition 4.3 (Variation diminishing property) The rational B-spline curve $\mathrm{p}(\mathrm{t}), \mathrm{t} \in\left[\mathrm{t}_{0}, \mathrm{t}_{\mathrm{n}}\right]$, defined by (4.17), crosses any (hyper) plane of dimension $\mathrm{N}-1$ no more times than it crosses the "control polygon" $p$ joining the control points $\left\{\mathrm{p}_{\mathrm{j}}\right\}_{\mathrm{j}=-1}^{\mathrm{n}+1}$. 
Proof. Examination of the coefficients $\alpha_{i}, \beta_{i}$ in (4.17) shows that

$$
\alpha_{i} \geq 0, \quad \beta_{i} \geq 0, \text { and } \alpha_{i}+\beta_{i} \leq 1
$$

Thus $\mathrm{Vi}$ and $\mathrm{W}_{\mathrm{i}}$ lie on the line segment joining $\mathrm{P}_{\mathrm{i}}, \mathrm{P}_{\mathrm{i}+1}$, where $\mathrm{Vi}$ is 'before' $\mathrm{W}_{\mathrm{i}}$. Also, we can write

$$
\mathrm{F}_{\mathrm{i}}=\left(1-\gamma_{\mathrm{i}}\right) \mathrm{W}_{\mathrm{i}-1}+\gamma_{\mathrm{i}} \mathrm{V}_{\mathrm{i}}
$$

Where $\gamma_{\mathrm{i}}=\left(\mathrm{h}_{\mathrm{i}-1} / \mathrm{r}_{\mathrm{i}-1}\right) /\left(\mathrm{h}_{\mathrm{i}-1} / \mathrm{r}_{\mathrm{i}-1}+\mathrm{h}_{\mathrm{i}} / \mathrm{r}_{\mathrm{i}}\right)$ and hence $0<\gamma_{\mathrm{i}}<1$. Thus the control polygon of the piecewise defined Bernstein-Bézier representation is obtained by 'corner cutting' of the B-spline control polygon, see Figure 4.4. Since th e piecewise defined Bernstein-Bézier representation is variation diminishing, it follows that the B-spline representation is also variation diminishing.

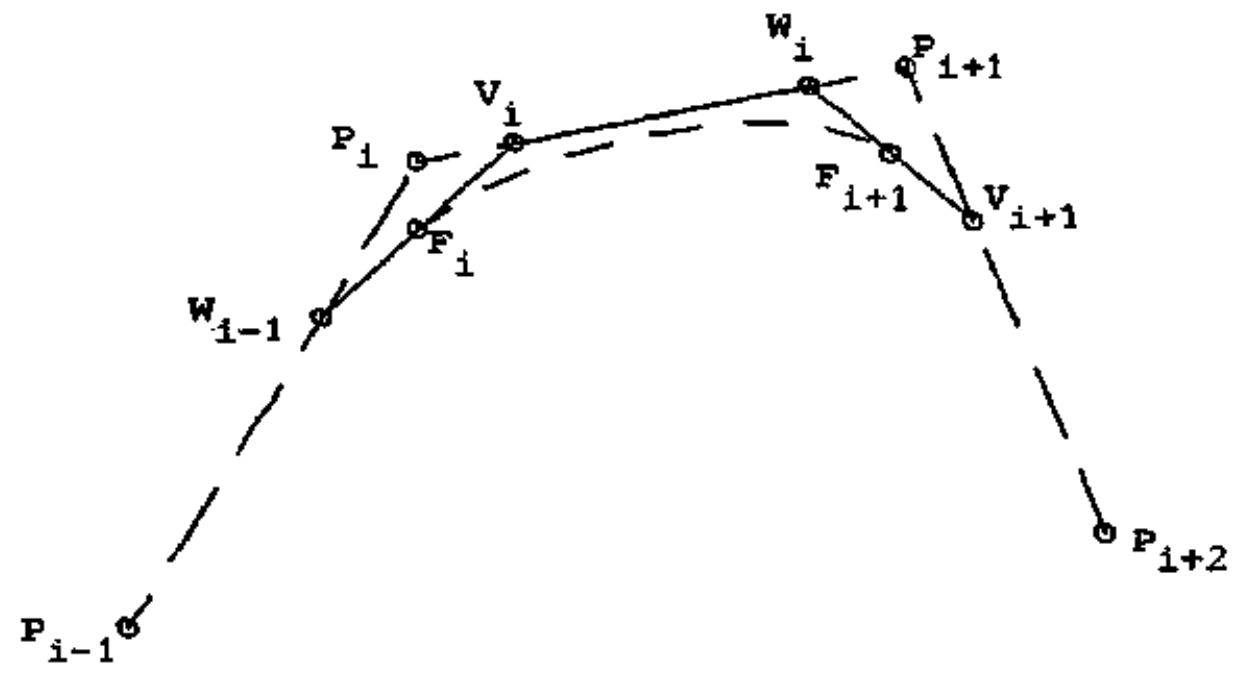

Figure 4.4 Corner cutting to obtain Bernstein-Bézier vertices

The tension properties of the rational B-spline representation are examined in the following two propositions:

Proposition 4.3 (Linear B-spline tension property) Let $r_{i} \geq r>2$, $\mathrm{i}=\mathrm{j}-2, \ldots, \mathrm{j}+1$. Then

$$
\lim _{r \rightarrow \infty}\left\|B_{j}-\phi_{j}\right\|=0
$$

where 


$$
\phi_{j}(t)=\left\{\begin{array}{cc}
\left(t-t_{j-1}\right) / h_{j-1}, & t_{j-1} \leq t<t_{j}, \\
\left(t_{j+1}-t\right) / h_{j}, & t_{j} \leq t<t_{j+1}, \\
0, & \text { otherwise, }
\end{array}\right.
$$

is the linear polynomial B-spline (see Figure 4.5)

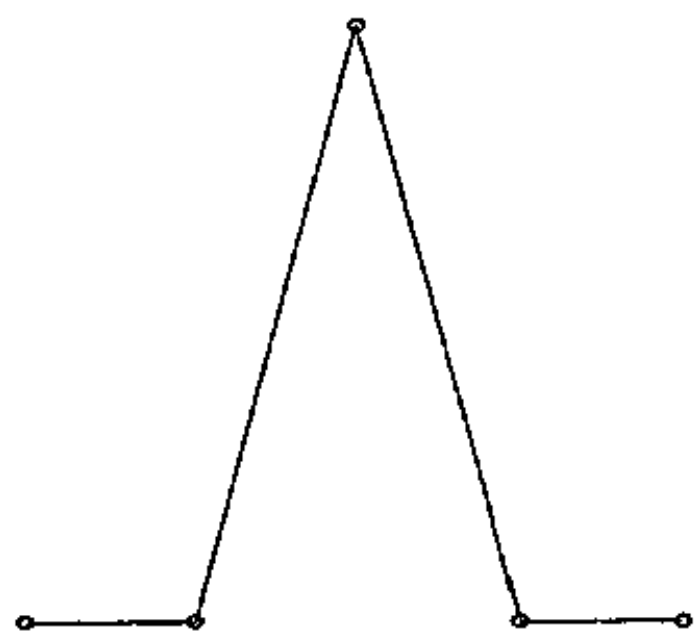

Figure 4.5 The linear polynomial B-spline

Proof. The rational B-spline defined by (4.12) can be expressed for $\mathrm{t} \in\left[\mathrm{t}_{\mathrm{i}}, \mathrm{t}_{\mathrm{i}+1}\right]$ as

$$
B_{j}(t)=(1-\theta) B_{j}\left(t_{i}\right)+\theta B_{j}\left(t_{i+1}\right)+e_{i}\left(t ; r_{i}\right),
$$

where

$$
\begin{gathered}
\mathrm{e}_{\mathrm{i}}\left(\mathrm{t} ; \mathrm{r}_{\mathrm{i}}\right)=\frac{\mathrm{h}_{\mathrm{i}} \theta(1-\theta)\left\{\left(\Delta_{\mathrm{i}}-\mathrm{B}_{\mathrm{j}}^{(1)}\left(\mathrm{t}_{\mathrm{i}}\right)\right)(\theta-1)+\left(\Delta_{\mathrm{i}}-\mathrm{B}_{\mathrm{j}}^{(1)}\left(\mathrm{t}_{\mathrm{i}+1}\right)\right) \theta\right\}}{1+\left(\mathrm{r}_{\mathrm{i}}-3\right) \theta(1-\theta)}, \\
\Delta_{\mathrm{i}}=\left(\mathrm{B}_{\mathrm{j}}\left(\mathrm{t}_{\mathrm{i}+1}\right)-\mathrm{B}_{\mathrm{j}}\left(\mathrm{t}_{\mathrm{i}}\right)\right) / \mathrm{h}_{\mathrm{i}},
\end{gathered}
$$

(cf. (2.9)-(2.11)). Here the $B_{j}\left(t_{i}\right)$ and $B_{j}{ }^{(1)}\left(t_{i}\right)$ values are defined by (4.13)-(4.15), where for $\mathrm{i}=\mathrm{j}-1, \mathrm{j}, \mathrm{j}+1$ they are dependent on $\mathrm{r}_{\mathrm{i}}, \mathrm{i}=\mathrm{j}-2$, $\ldots, j+1$. Examination of the coefficients (4.15) reveals that $\hat{\mu}_{j}, \hat{\lambda}_{j}$, and hence the $B_{j}{ }^{(1)}\left(t_{i}\right)$ are bounded and that

$$
\lim _{r_{j-2} \rightarrow \infty} B_{j}\left(t_{j-1}\right)=\lim _{r_{j+1} \rightarrow \infty} B_{j}\left(t_{j+1}\right)=0, \lim _{r_{j-1}, r_{j} \rightarrow \infty} B_{j}\left(t_{j}\right)=1
$$

It is then a simple matter to show that $\lim \left\|\mathrm{e}_{\mathrm{i}}\right\|=0$ and that (4.23) holds. $\square$ 
Remark 4.4 From (4.28) there follow the more precise results that

$$
\begin{array}{ll}
\lim _{r_{j+1} \rightarrow \infty}\left\|B_{j}\right\|=0 & \text { on }\left[t_{j+1}, t_{j+2}\right], \\
\lim _{r_{j-1}, r_{j}, r_{j+1} \rightarrow \infty}\left\|B_{j}-\phi_{j}\right\|=0 & \text { on }\left[t_{j-2}, t_{j}\right], \\
\lim _{r_{j-2}, r_{j-1}, r_{j} \rightarrow \infty}\left\|B_{j}-\phi_{j}\right\|=0 & \text { on }\left[t_{j-2}, t_{j}\right], \\
\lim _{r_{j-2} \rightarrow \infty}\left\|B_{j}\right\|=0 & \text { on }\left[t_{j-2}, t_{j-1}\right] .
\end{array}
$$

An immediate consequence of Proposition 4.3 (and Remark 4.4) is:

Corollary 4.5 (Global tension property) Let $r_{i} \geq r>2, \quad i=-2, \ldots, n+1$, and let $\mathrm{P}$ denote the control polygon, defined explicitly on $\left[\mathrm{t}_{\mathrm{i}}, \mathrm{t}_{\mathrm{i}+1}\right]$, $i=-1, \ldots, n$, by

$$
\mathrm{P}(\mathrm{t})=(1-\theta) \mathrm{P}_{\mathrm{i}}+\theta \mathrm{P}_{\mathrm{i}+1}, \theta(\mathrm{t})=\left(\mathrm{t}-\mathrm{t}_{\mathrm{i}}\right) / \mathrm{h}_{\mathrm{i}}
$$

Then the rational $\mathrm{B}$-spline representation (4.17) converges uniformly to $\mathrm{P}$ on $\left[\mathrm{t}_{-1}, \mathrm{t}_{\mathrm{n}+1}\right]$ as $\mathrm{r} \rightarrow \infty$.

Corollary 4.5 could be proved directly by studying the behaviour of the Bernstein-Bézier control points in (4.19) as $r \rightarrow \infty$. We follow this approach in the proof of the final proposition.

Proposition 4.6 (Local tension property) Consider an interval $\left[t_{k}, t_{k+1}\right]$ for a fixed $k \in\{0, \ldots, n-1\}$ and let

$$
\left.\begin{array}{c}
\mathrm{Q}_{\mathrm{K}}=(1-\mu) \mathrm{P}_{\mathrm{K}}+\mu \mathrm{P}_{\mathrm{K}+1}, \\
\mathrm{Q}_{\mathrm{K}+1}=\lambda \mathrm{P}_{\mathrm{K}}+(1-\lambda) \mathrm{P}_{\mathrm{K}+1},
\end{array}\right\}
$$

denote two distinct points on the line segment of the control polygon joining $\mathrm{P}_{\mathrm{K}}, \mathrm{P}_{\mathrm{K}+1}$, where

$$
\left.\begin{array}{l}
\lambda=\mathrm{h}_{\mathrm{k}+1} / \mathrm{r}_{\mathrm{k}+1} /\left(\mathrm{h}_{\mathrm{k}-1} / \mathrm{r}_{\mathrm{k}-1}+\mathrm{h}_{\mathrm{k}+1} / \mathrm{r}_{\mathrm{k}+1}+\mathrm{h}_{\mathrm{k}}\right), \\
\mu=\mathrm{h}_{\mathrm{k}-1} / \mathrm{r}_{\mathrm{k}-1} /\left(\mathrm{h}_{\mathrm{k}-1} / \mathrm{r}_{\mathrm{k}-1}+\mathrm{h}_{\mathrm{k}+1} / \mathrm{r}_{\mathrm{k}+1}+\mathrm{h}_{\mathrm{k}}\right),
\end{array}\right\}
$$

(Note that $\mathrm{Q}_{\mathrm{k}}$ is 'before' $\mathrm{Q}_{\mathrm{k}+1}$ since $\lambda+\mu<1$.) Then the rational B-spline representation (4.17) converges uniformly to $Q$ on $\left[\mathrm{t}_{\mathrm{k}}, \mathrm{t}_{\mathrm{k}+1}\right]$ as 
$\mathrm{r}_{\mathrm{K}} \rightarrow \infty$, where

$$
\mathrm{Q}(\mathrm{t})=(1-\theta) \mathrm{Q}_{\mathrm{K}}+\theta \mathrm{Q}_{\mathrm{K}+1}, \quad \theta(\mathrm{t})=\left(\mathrm{t}-\mathrm{t}_{\mathrm{K}}\right) / \mathrm{h}_{\mathrm{K}} .
$$

Proof. It is a simple matter to show, in (4.15), that

$$
\begin{aligned}
& \lim _{\mathrm{r}_{\mathrm{K}} \rightarrow \infty} \lambda_{\mathrm{k}}=\lim _{\mathrm{r}_{\mathrm{K}} \rightarrow \infty} \mu_{\mathrm{k}+1}=0, \\
& \lim _{\mathrm{r}_{\mathrm{K}} \rightarrow \infty} \mu_{\mathrm{k}}=\mu \text { and } \lim _{\mathrm{r}_{\mathrm{K}} \rightarrow \infty} \lambda_{\mathrm{k}+1}=\lambda .
\end{aligned}
$$

Thus, in the Bernstein-Bézier representation (4.19) on $\left[\mathrm{t}_{\mathrm{k}}, \mathrm{t}_{\mathrm{k}+1}\right]$, we have

$$
\lim _{\mathrm{r}_{\mathrm{K}} \rightarrow \infty} \mathrm{F}_{\mathrm{k}}=\mathrm{Q}_{\mathrm{k}} \text { and } \lim _{\mathrm{r}_{\mathrm{K}} \rightarrow \infty} \mathrm{F}_{\mathrm{k}+1}=\mathrm{Q}_{\mathrm{k}+1}
$$

Moreover, the Bernstein-Bézier representation can be expressed as

$$
\mathrm{P}(\mathrm{t})=\mathrm{P}_{\mathrm{k}}\left(\mathrm{t} ; \mathrm{r}_{\mathrm{k}}\right)=\ell_{\mathrm{k}}\left(\mathrm{t} ; \mathrm{r}_{\mathrm{k}}\right)+\mathrm{e}_{\mathrm{k}}\left(\mathrm{t}, \mathrm{r}_{\mathrm{k}}\right), \mathrm{t} \in\left[\mathrm{t}_{\mathrm{k}}, \mathrm{t}_{\mathrm{k}+1}\right]
$$

as in (2.9), where it can be shown that

$$
\lim _{r_{K} \rightarrow \infty}\left\|Q-\ell_{k}\right\| \leq \lim _{r_{K} \rightarrow \infty}\|Q-P\|+\lim _{r_{K} \rightarrow \infty}\left\|e_{k}\right\|=0 \quad \text { on } \quad\left[t_{k}, t_{k+1}\right]
$$

which completes the proof.

Examples 4.7 Consider the data set in $\mathrm{R}^{2}$, identical to that of the interpolatory examples 3.4, where the data now define the control points of the rational B-spline representations. Figures 4.6 and 4.7 illustrate the effect, respectively, of progressive global and local increases in the tension parameters. The results confirm the analysis of Corollary 4.5 and Proposition 4.6
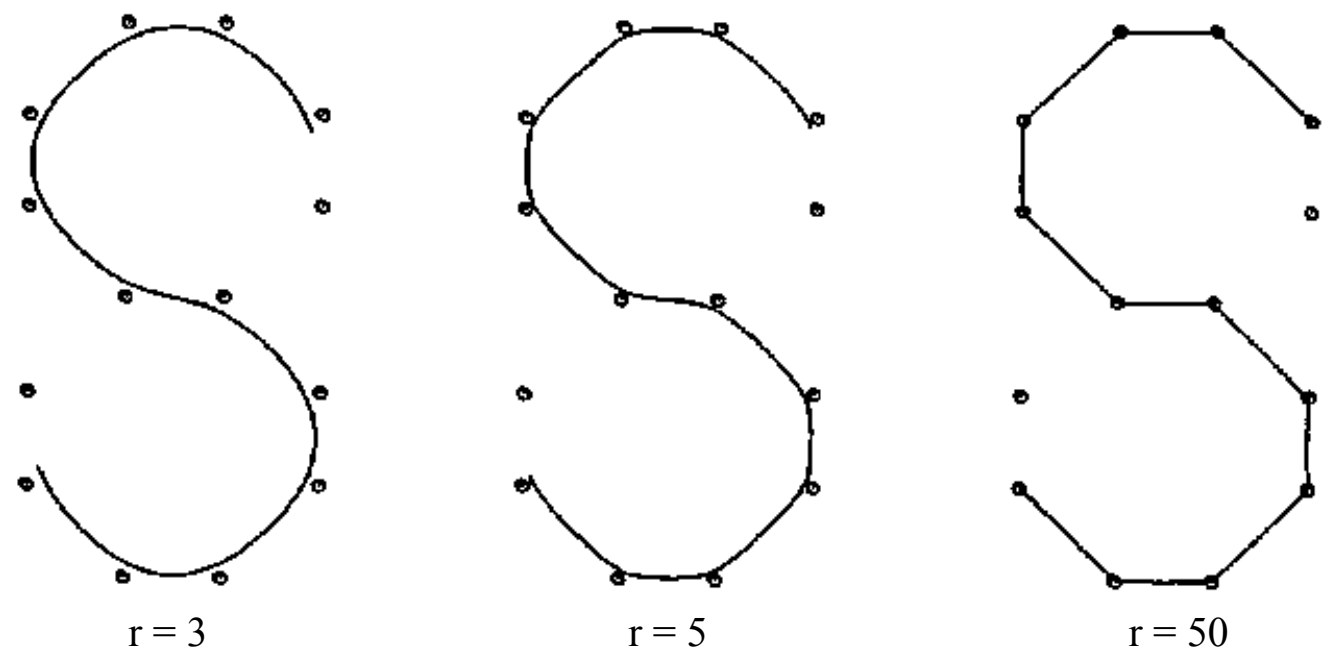

Figures 4.6 Rational B-spline curves with global tension $r_{i}=r$ 

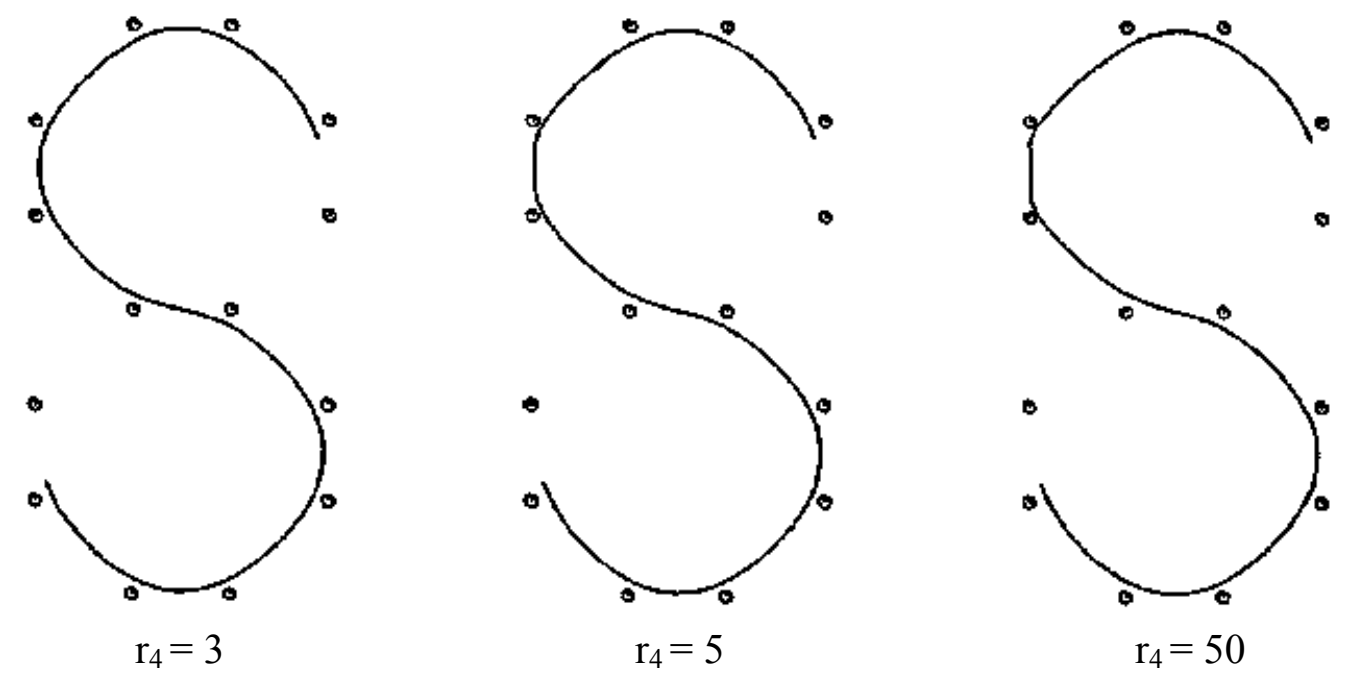

Figures 4.7 Rational B-spline curves with tension $r_{4}$ varying

\section{Concluding Remarks}

An analysis of a rational cubic tension spline has been developed with a view to its application in CAGD. We have found it appropriate to construct a rational form which involves just one tension parameter per interval, although clearly the rational form defined by (2.1) could be generalized. One advantage of the use of $\mathrm{C}^{2}$ parametric continuity, compared with that of more general geometric $\mathrm{GC}^{2}$ continuity, will become apparent in the application of such a rational spline method for surfaces. In this case we would propose to follow the approach of Nielson [Nielson '86], in the use of the spline blended methods of Gordon [Gordon '71]. Nielson proposes a spline blended surface of $\mathrm{GC}^{2}$ v-splines but observes that only $\mathrm{GC}^{1}$ continuity results from such a spline blend of $\mathrm{GC}^{2}$ curves. However, the use of parametric $\mathrm{C}^{2}$ curves in the blend will alleviate this loss of continuity.

\section{Acknowledgements}

The authors are pleased to acknowledge helpful discussions with N. Dyn and D. Levin in the development of this paper. 


\section{References}

Barsky, B.A. and Beatty, J.C. (1983), Local control of bias and tension in beta-splines, ACM Trans, on Graphics 2, 109-134.

Böhm, W. (1987), Rational geometric splines, Computer Aided Geometric Design 4, 67-77.

Cline, A. (1974), Curve fitting in one and two dimensions using splines under tension, Comm. ACM 17, 218-223.

Delbourgo, R. and Gregory, J.A. (1983), $C^{2}$ rational quadratic spline interpolation to monotonic data, IMA J. Numer. Anal. 3, 141-152.

Delbourgo, R. and Gregory, J.A. (1985), Shape preserving piecewise rational interpolation, SIAM J. Sci. Stat. Comput. 6, 967-976.

Demko, S. (1977), Inverses of band matrices and local convergence of spline projections, SIAM J, Numer. Anal. 14, 616-619.

Goodman, T.N.T. (1988), Shape preserving interpolation by parametric rational cubic splines, Proc. Int. Conf. on Numerical Mathematics, Int. series Num. Math. 86, Birkhäuser Verlag, Basel.

Goodman, T.N.T. (1989), Shape preserving representations, in Lyche, T. and schumaker, L., eds., Mathematical Methods in Computer Aided Geometric Design, Academic Press.

Gordon, W.J. (1971), Blending function methods of bivariate and multivariate interpolation and approximation, SIAM J. Num. Anal. 8, 158-177.

Gregory, J.A. (1986), Shape preserving spline interpolation, CAD 18, 53-57.

Nielson, G.M. (1975), Some piecewise polynomial alternatives to splines under tension, in Barnhill, R.E. and Riesenfeld, R.F., eds., Computer Aided Geometric Design, Academic Press, New York.

Nielson, G.M. (1984), A locally controllable spline with tension for interactive curve design, Computer Aided Geometric Design 1, 199-205.

Nielson, G.M. (1986), Rectangular v-splines. IEEE Computer Graphics and Applies. 6, 35-40. 
Preuss, S. (1976), Properties of splines in tension, J. Approx. Theory 17, 86-96.

Preuss, S. (1979), Alternatives to the exponential spline in tension, Math. Comp. 33, 1273-1281.

Schaback, R. (1973), Spezielle rationale Splinefunktionen, J. Approx. Theory 7, 281-292.

Schweikert, D. (1966), An interpolation curve using splines in tension, J. Math, and Phys. 45, 312-317.

Späth, H. (1974), Spline Algorithms for Curves and Surfaces, Utilitas Mathematica Pub. Inc., Winnipeg. 